\title{
A CONVIVÊNCIA FAMILIAR DO PORTADOR DO HIV E DO DOENTE COM AIDS
}

\author{
FAMILY LIVING OF PEOPLE WITH HIV AND AIDS
}

Maguida Costa Stefanelli

Dulce Maria Rosa Gualda Aidê Ferreira Ferraz ${ }^{3}$

RESUMO: O número de pessoas infectadas com o HIV continua em franca ascensão, e a AIDS vem afetando a vida das pessoas e a qualidade das relações humanas, impondo a necessidade de revisão de valores, crenças e até mesmo mudanças de estilo de vida. Preocupa-nos, no presente estudo, compreender a convivência familiar do portador do HIV ou doente com AIDS. Apresentamos um estudo de caso etnográfico, utilizando fases da observação participante e entrevista. Destes extraímos alguns domínios culturais que são: sentimentos em relação à família e à vida antes e depois do diagnóstico; processo de comunicação do portador do HIV/ AIDS com os familiares; expressões de apoio familiar após as manifestações clínicas da AIDS; resistência na aceitação da homossexualidade pela família. O foco central do estudo aponta para os sentimentos de solidão e isolamento do portador do HIV/AIDS e a relevância do suporte familiar no processo de adaptação a uma nova condição de vida. Foram evidenciadas dificuldades no relacionamento entre o portador do HIV/AIDS e seus familiares. Este estudo aponta para a necessidade de atuação da enfermagem, juntamente com outros profissionais da saúde, para que possam oferecer aos familiares, elementos que possibilitem o encontro de caminhos para a humanização da convivência familiar, quando um dos membros é portador do HIV ou doente com AIDS. Tal contexto demanda a adoção de estratégias de intervenção fundamentada em abordagem integral e humanizada, juntamente com outros profissionais, que contemple também o cuidado da família das pessoas que vivem com HIV/AIDS, além delas próprias.

PALAVRAS CHAVE: Família; Cuidados de enfermagem; HIV.

\section{INTRODUÇÃO}

O HIV é hoje um desafio para o homem e continuará sendo por tempo indeterminado, desafiando-o além do final do milênio. O número de portadores de HIV continua aumentando em âmbito mundial e trazendo consigo problemas e pânico não só para quem o adquire como para aqueles à sua volta - familiares, amigos e sociedade (Bunting,1996 e Meneghin,1996)

Os índices que já eram alarmantes, aumentaram ainda mais. O Brasil já ocupa o segundo lugar na prevalência da AIDS. Nos círculos da área da saúde levanta-se a hipótese de que uma das razões deste aumento seja a recente descoberta do "coquetel anti-AIDS" e a crença surgida na população de que ele significa a cura da AIDS. Esta crença fez, também, com que muitas pessoas soropositivas ou com AIDS procurassem médicos e se identificassem na procura de receita para obtenção do coquetel com o objetivo de cura em mente, aumentando os índices estatísticos.

A AIDS vem afetando a vida das pessoas e a qualidade das relações humanas impondo a necessidade de revisão de valores, crenças e até mesmo mudança de estilo de vida, que envolve aspectos sociais, econômicos, psicológicos, culturais entre outros.

\footnotetext{
Professor Titular pela USP. Doutor. Saúde Mental e Comunicação em Enfermagem.. Pesquisador Visitante Escola de Enfermagem da UFMG - FAPEMIG (1997-98) e Pesquisador Visitante da UFPR (1998-2000).

2 Professor Doutor. Enfermagem Obstétrica e Saúde da mulher. Departamento ENP / Escola de Enfermagem da Universidade de São Paulo(USP).

3 Doutor. Enfermagem Básica e Comunicação. Departamento ENB / Escola de Enfermagem da Universidade Federal de Minas Gerais.
} 
O preconceito que envolve a AIDS está sendo veiculado sub-liminarmente na mídia e é encontrado, também, nos trabalhos de pesquisa (Meneghin,1996). Nos resta a pergunta: será preconceito ou medo de algo que não tem cura, que ainda mata?

Acreditamos que o preconceito foi muito reforçado pelo que se constatou e noticiou quando do aparecimento da AIDS. Ela era considerada uma doença de homossexuais o que acentuava de forma mais contundente o preconceito da sociedade e, portanto, da família em relação a homossexualidade.

Face às imposições que são exigidas das pessoas $\mathrm{HIV}^{+}$ou doente com AIDS surge a necessidade de reestruturação do seu estilo de vida.

Com estas preocupações em mente indagamo-nos: o que estaria levando famílias a abandonarem seu familiar doente com AIDS e fazendo com que os próprios doentes escondam que são portadores dessa síndrome? Como estas famílias reagiriam hoje, se soubessem que o índice mais elevado de soropositivos e de pessoas doentes com AIDS está incluindo a classe dos heterossexuais e aumentando, também, entre as mulheres em geral, inclusive as com companheiro fixo e não apenas entre prostitutas?

Causa estranheza o fato deste preconceito persistir até hoje, como podemos observar num estudo feito junto a universitários e presidiários. Entre os universitários predominou o mito de que a AIDS é doença de homossexuais, prostitutas e usuários de drogas (Meneghin,1996), o que, por si só, justifica a necessidade de mais pesquisas a respeito do tema.

Nosso objetivo com este estudo é descrever, compreender a convivência familiar do portador de HIV/AIDS.

\section{MÉTODO}

Trata-se de um estudo de caso tipo etnográfico, que permite um estudo de diferentes variáveis de modo profundo num contexto que é natural para a pessoa. Não a retira de seu ambiente habitual e não se introduz outra variável.(Ludke;André,1996).

\section{Informantes}

Os informantes do estudo são constituídos de quatro pessoas, integrantes de um grupo de auto-ajuda, do qual uma das pesquisadoras participa como voluntária. Este grupo foi observado no local em que ocorrem suas reuniões e algumas entrevistas realizadas nas residências dos informantes.

O grupo é formado por pessoas da comunidade com HIV/AIDS ou não e alguns profissionais interessados pelo assunto e na compreensão da vivência das pessoas acometidas por HIV/AIDS.

A participação neste estudo foi voluntária, após explanação sobre o mesmo e ter-se assegurado aos informantes o anonimato e sigilo. Foi explicitado o uso que se faria dos dados, bem como o retorno dos resultados para o grupo e a não implicação em ônus para os mesmos. Só após obteve-se o consentimento assinado.

\section{Obtenção dos Dados}

Utilizou-se para a coleta de dados a observação participante, segundo Leininger (1991) e a entrevista, quando necessária, segundo Spradley (1979) considerando-se as perguntas descritivas, estruturais e de contraste.

A observação participante seguiu os passos: observação; observação com participação; participação com alguma observação e observação reflexiva (observação-participação-reflexão) e os dados foram organizados em descritores e temas culturais (Leininger, 1991).

\section{DESCRITORES CULTURAIS}

Os descritores culturais identificados são pertinentes aos sentimentos da pessoa com $\mathrm{HIV}^{+}$ou doente com AIDS, em relação a vida antes e ao receber o diagnóstico e depois deste. O processo de comunicação e relacionamento das pessoas com HIV/AIDS e seus familiares, expressões de apoio familiar após o diagnóstico e suas manifestações clínicas e ainda as reações dos familiares quanto a homossexualidade, quando presente. 


\section{Sentimentos em relação a vida e a família antes e depois do diagnóstico}

A partir da análise dos relatos dos sujeitos, constatamos que a evolução do medo para a ansiedade, desespero e angústia inicial e, ainda, a oscilação de humor estão presentes antes, desde a decisão de se fazer o exame laboratorial e depois, quando a pessoa recebe o diagnóstico de que é soropositivo ou de que tem AIDS.

"Sempre conheci muito bem meu corpo. Tinha alguma coisa andando dentro de mim, eu senti que tinha alguma coisa errada".

"Eu passei por uma angústia inicial do ELISA e depois que recebi o resultado, passei por outra angústia...

"Eu imaginava assim: até o final do ano estou morto".

"Você não vai poder transar mais... foi uma coisa muito pesada".

"Porque você tá desesperado, tá desestruturado, ninguém nunca falou que você vai morrer com 27 anos".

"É só viver o desespero... a agonia".

"Na hora do diagnóstico é como uma pancada na cabeça, uma anestesia,,, fiquei abobalhada. A única coisa que falei foi: o que faço agora?"

É comum surgirem sentimentos de depressão, solidão e perda do significado da vida e desesperança. Estes sentimentos surgem da ambivalência do contar ou não para amigos, familiares ou um familiar específico. A quem contar? Sob o impacto do diagnóstico, mas necessitando urgentemente expressar a sensação de pressão interior, de opressão e de vazio, alguns procuram ajuda de grupos de "auto ajuda", de convivência de pessoas com HIV/AIDS ou até de profissionais envolvidos com o assunto, grupos religiosos e, às vezes, um familiar. Outros se isolam, bebem, pensam em suicídio.

"Saí do consultório e liguei para minha irmã, em choque. Ela não podia sair do trabalho. Entrei num buteco e bebi todas..."

"Eu fiquei maluco. Corri todas as ONGs, ninguém soube me explicar sobre o exame..."

"Quando recebi o resultado positivo eu passei por outra angústia: a espera do resultado do Western-Blood".

"A sensação que eu tinha era que a cada dia eu estava perdendo mais um dia, mais um dia..."

"...Então já que entrei neste barco furado, eu que continue nele sozinho".

O isolamento e a depressão, às vezes, surgem pelo fato da "pessoa doente" não ter com quem falar, temendo a reação que possa provocar.

"A solidão do soropoositivo é uma coisa que dói muito. O abandono também é pesado".

Uma das informantes com companheiro fixo, casada, descreveu seu sentimentos de desesperança e a perda do sentido da vida sob o impacto do diagnóstico.

"Achava que nunca ia acontecer comigo... foi uma coisa".

"Fiquei sem ação e sem reação... sem pensamento, porque eu não estava preparada para pensar em AIDS, pra mim".

"Fiquei sem chão... como se ele abrisse em baixo do meu pé".

"É como se tivesse só uma passagem de ida, sem volta, carimbada".

É o que alguns autores chamam de "morte anunciada" (Silva,1996). A morte é algo que faz parte do nosso cotidiano mas o sentimento de finitude não é habitual no nosso pensar. Em geral, só quando um acontecimento nos alerta para a morte é que refletimos mais sobre o assunto. Quando a pessoa recebe o diagnóstico de que é portador de HIV/AIDS passa a conviver com a sua finitude de forma mais íntima, mais próxima.

"A preocupação chega a ser uma norma pra gente. Ao receber o diagnóstico, toda pessoa imediatamente, tem um limite: a morte, que é colocada o tempo todo".

"A gente tem os dias da AIDS... só pensa nela, na morte, fica deprimido.

"Gostaria de contar mais com minha família... moro afastado... mas infelizmente na situação da minha família eu sinto mais medo do que qualquer outra coisa. Não medo de contar, mas medo de perda associado à minha mulher". 


\section{Processo de comunicação e relacionamento do portador do HIV/AIDS com os familiares}

A situação conflitiva do portador do HIV, ao decidir a quem da família ou do círculo de amigos contar; em quem confiar, a quem pedir ajuda, com quem falar sobre o que vivencia, afetou também os processos de comunicação e relacionamento com as pessoas.

Alguns deles tentam por muito tempo suportar sozinho o que sofrem. Chega um determinado momento que, como ser humano que é, não tolera mais a opressão, a angústia, a solidão e toma a decisão de contar a alguém. Aí surge o dilema: "para quem"? Algumas falas retratam bem esta situação.

Ao indagar aos informantes sobre a sua comunicação e o seu relacionamento com a família surgiram informações tanto de aceitação como de rejeição.

“...Bebi... cheguei na casa dela (irmã)... e assim em prantos... foi barra pesada! Mas ela me deu uma força fantástica! Me ouviu e aí resolvemos procurar um infectologista".

....'Aí eu fui morar com o irmão em... Foi outro erro. Eu não estava preparado, eu fui até para trabalhar com ele... ele também não estava preparado. Evitava mil coisas... contato físico nenhum.. assim terrível".

"A primeira pessoa que falei foi pra minha irmã, mas por mais esforço que ela faça ela não me aceita.

"Sentia muita cobrança, me culpavam pela doença".

"Na minha família meu relacionamento é ruim. Lá em casa nosso relacionamento é muito distante. As pessoas que sou mais próximo é minha irmã, mas tem essa falta de aceitação".

"Senti rejeição".

"Teve falta de aceitação".

O sofrimento da mãe, ao saber que contraiu o vírus do HIV do marido e que não queria revelar aos seus filhos, sua situação, é evidenciado abaixo.

"As crianças falavam vamos fazer isso, aquilo...daqui a um ano. Eu pensava: eu não vou mais estar aqui. Minha filha estava grávida e eu pensando que não podia pegar meu neto no colo, que não podia beijar... era uma barra".

\section{Expressões de apoio familiar após o diagnóstico, suas manifestações clínicas e quanto a homossexualidade}

As pessoas com HIV/AIDS manifestam em várias falas sentimentos em relação a família e como gostariam que elas reagissem ao saber que elas são portadores do HIV ou estão com AIDS.

Algumas pessoas das famílias dos informantes do estudo, em contraposição àquelas que não queriam nem ouvir o familiar afetado por HIV/AIDS, expressaram frases de apoio, aceitação e conforto.

"Quando ficaram sabendo do HIV deram a maior força, não tinha tratamento diferente. Comentava sobre meus amigos, da minha vida, mas nem tanto em grandes detalhes".

"Aí teve o caso da minha prima que ficou doente (AIDS), ela mudou para nossa casa...

"Minha prima era atrevida mesmo. Ela falou pra minha mãe que eu também era portador. Comigo não mudou nada... todo mundo chegava, conversava legal".

"Minha mãe procura me deixar o mais leve possível", e eu sei que por trás ela chora muito".

"Elas sempre perguntam, acompanham também".

"Minha mãe sempre soube que eu era homossexual... dei um toque para ela e ela disse: Não preocupa não meu filho, Deus é que guarda"...

"Meus pais tinham menos preconceito da minha doença do que os próprios irmãos. 


\section{Resistência na aceitação da homossexualidade}

Alguns familiares aceitam que um ser da família seja portador de HIV/AIDS, oferecem apoio, estimulam para uma vida mais saudável, mas não aceitam sua condição de homossexual. Aí surge o preconceito que é expresso de várias maneiras.

"Acho que foi muito negativo a revelação para minha irmã, ela não me aceita como eu sou"!

"É o tempo todo o lance das roupas. Ela chegava para mim só para malhar, não é pra fazer elogio. A maioria das vezes era só para malhar.

"...Se meu irmão usar camisa xadrezinha... tudo bem, normal. Se eu usar é coisa de bicha. Ah, cuidado com a AIDS, eu já sabia que você estava contaminado".

"Não é um espaço onde fico a vontade (sua casa), não posso falar o que eu quero pelo telefone".

"É lógico que eles (pais) sacam, mas não me dão liberdade para falar.

Às vezes, a resistência na aceitação da homossexualidade existe no próprio portador do vírus ou doença.

"Sou assumido em minhas coisas, mas por exemplo, eu não sou assumido nem como positivo nem como homossexual para o meu pai e minha mãe".

\section{TEMAS CULTURAIS}

Após a elaboração dos descritores culturais, a análise dos mesmos, releitura das informações, alguns temas emergiram como mais relevantes na convivência familiar dos portadores de HIV/AIDS. São eles: "sentimentos de solidão e isolamento" e "relevância do suporte familiar" no processo de adaptação a uma nova condição de vida.

\section{“SENTIMENTOS DE SOLIDÃO E ISOLAMENTO”.}

Da leitura dos domínios apresentados percebemos, como algo profundo, que nos toca de perto, o quanto os informantes, deste exercício de aprendizado etnográfico, se sentem sós, abandonados, culpados, sem chão para pisar, com perda do sentido da vida. É comum surgir a pergunta "e agora o que faço?" e ,como disse um dos participantes: "a única coisa que consegui falar foi isso". Pessoas de nosso estudo que são casadas, têm filhos e não sabem bem que rumo dar às suas vidas expressaram:

"Aquilo pra mim... foi... eu acho que fui no subsolo... assim eu cheguei de uma vez".

"Prá que, quanto menos pessoas passassem o que eu estou passando sentissem o que eu estou sentindo, não pela situação de morte, mas pela situação de culpa".

Um deles gostaria que seus filhos tivessem mais idade para poder se abrir com eles. Ao mesmo tempo vem o desespero "o que acontecerá com eles"?

Com o impacto do diagnóstico a pessoa tem a "vivência do encasulamento" que consiste principalmente no isolamento da pessoa, quando é comum associarem-se sentimentos de depressão, baixa auto-estima, de revolta. Lembra o que afirma SILVA (1996) "uma espécie de hibernação para digerir e elaborar algo difícil".

Quando o portador HIV/AIDS, estabelece "um senso de conexão com os outros", ele procura relacionamento com outras pessoas do círculo familiar ou não. Como pessoa ele sente necessidade de se relacionar com alguém para compartilhar sua experiência (Silva, 1996).

Pela convivência com os portadores do HIV/AIDS, percebemos que esses procuram primeiro os amigos, grupos de auto-ajuda para depois voltarem-se para a família, de quem esperam compreensão e afeto. É a necessidade de amar e ser amado que exige ser satisfeita. O ser humano é um ser de relação não existe como homem sem entrar em comunicação com seus semelhantes. Mesmo quando se isola, espontaneamente dos demais, vive momentos de solidão, tenta não se comunicar com ninguém. Mas, mesmo assim, está nos transmitindo seus sentimentos, suas emoções e seus temores (Stefanelli,1993). 
"Na maioria do tempo, eu sempre procurava tá só comigo mesmo, ou vendo televisão, entendeu"?

Um casal sob o impacto da notícia do diagnóstico tentou realizar o enfrentamento sozinho, mas depois de muito sofrimento procuraram o grupo.

"Aí, depois a gente conheceu o grupo, começou a se inteirar mais. Então você passa a adquirir mais conhecimento... Tem melhorado nossa condição de vida."

Percebemos que a solidão e isolamento são vivenciados, em tempos diferentes pelos informantes da pesquisa. Eles caminham por momentos de dúvida, até que não suportando mais estes sentimentos procuram apoio em grupos de auto-ajuda, de membros da família. Esses reagem de forma variada, nem sempre correspondendo às suas expectativas. A necessidade de apoio familiar torna-se cada vez mais imperiosa.

\section{“RELEVÂNCIA DO SUPORTE FAMILIAR”}

A importância do suporte familiar no processo de adaptação a uma nova condição de vida pôde ser evidenciada em diversas falas, em diferentes momentos, do diagnóstico às manifestações clínicas. Desde o como contar, a quem contar até quem vai cuidar de mim, bem como sobre quais as possibilidades de ajuda que a família pode dispor .

A pessoa com HIV/AIDS após passar pela fase de querer manter para si o diagnóstico e procura amigos, grupos e, alguns, só em fase mais adiantada procuram a família. Antes, porém passam por uma fase de dúvida e analisam o que pode acontecer. Alguns informantes evidenciam a necessidade de suporte familiar, embora reconheçam que irão afetar a vida da familia, como um todo.

“...Minha família tem toda sua vida”.

“... Não posso me dar a esse luxo. Minha mãe já levanta às cinco para trabalhar, meu irmão tá começando a vida agora, tem uma filha... Minha cunhada trabalha também..."

"É mudar o ritmo de vida delas para ficar cuidando de mim. Isso me preocupa muito".

Passado o momento de dúvida procuram apoio familiar e valorizam este.

"Tem um irmão que faz muita pergunta, até mesmo pra médica, né. É... ela estando lá ele pergunta sempre..".

"Então, assim a participação deles tem sido muita... Graças a Deus. Esse apoio é fundamental".

"Eu não sei se é pela questão de tá doente agora, de estar com necessidade de ter família do lado, mas francamente eu descobri que minha família é muito importante para mim".

"Foi um reencontro tá, como eu te falei... Não é nem relação a doença.

Algumas pessoas verbalizam o que gostariam que a família fizesse.

"Eu quero é que me dê forças, pelo amor de Deus".

"Se eles fossem um pouco mais firmes poderiam chegar para mim e dizer: eu vou falar com você, você vai sentar e você vai me escutar. Pode acontecer isso...isso..."

A relevância do apoio dos familiares fica evidenciada nestas falas e comentários, embora nem sempre este apoio ocorra de forma incondicional ou atendendo às reais necessidades das pessoas.

\section{CONSIDERAÇÕES FINAIS}

Revendo todo o estudo percebemos que às vezes as reações dos sujeitos portadores de HIV/AIDS são paradoxais, bem como a de seus familiares. Esse paradoxo aparece de forma quase constante associado à falta de informação ou orientação não só por parte dos familiares como dos profissionais de saúde; desde o momento da procura de ajuda para o diagnóstico, perpassando pelo impacto do diagnóstico e o que fazer após.

Em BURY (1997) encontramos apoio para nossas considerações. Este autor ao tratar da doença crônica distingue três aspectos da experiência de adoecer:

- a desintegração biográfica ocasionada pela doença e as tentativas iniciais da pessoa ao lidar com as incertezas; 
- o impacto do tratamento na vida diária, quando assume importância vital a adoção de informações sobre o vírus e a doença;

- a adaptação e enfrentamento da doença que ocorrem quando as pessoas respondem e tentam reconstruir uma vida normal.

Para o autor, as respostas para lidar com a situação são sintetizadas em termos de "coping", estratégia e estilo. Os mecanismos envolvidos no "coping" nos remetem às estratégias que as pessoas adotam para enfrentar os problemas que a sua condição, de doente crônico, impõe.

Os doentes que se adaptam são aqueles capazes de mobilizarem recursos mais intensamente. Esses recursos referem-se a energia e aos esforços individuais gastos na sua adaptação quando eles se direcionam, também, ao nível de apoio disponibilizado na rede social, na qual tem papel preponderante a família.

Por outro lado os recursos se relacionam intimamente com o desenvolvimento de diferentes estilos de se lidar com a doença. O desempenho que é requerido das pessoas que vivem condição de doença crônica envolve o planejamento, treinamento e avaliação de ações. Essa é feita tendo em mente outras pessoas uma vez que, segundo Goffman, citado em Bury (1997), a identidade é um produto da ação e da resposta social.

Como afirma Gualda (1998), a doença crônica têm múltiplas dimensões e gera uma gama de demandas que assumem a conotação de desafios ao desenvolvimento de cada um, na tentativa de adaptação à nova condição de vida que se apresenta. Essas demandas sofrem interferências da natureza da doença, recursos sociais e econômicos afirmando que a singularidade de ser ou estar doente depende do ambiente socioeconômico e cultural.

Precisamos aprender a conviver com a complexidade do outro, como afirma Ferraz(1996): "Permitir a complexidade do outro talvez seja um dos mais valiosos segredos das relações interpessoais bem sucedidas porque implica a aceitação desse outro exatamente como ele é, sem as máscaras impostas pelo cotidiano social."

A família também tem de ser cuidada para que não se desestruture e possa encontrar caminhos para a humanização da convivência, efetuando também reavaliações e adaptações em seu estilo de vida.

ABSTRACT: the present study has the goal to understand how is the family living of people with HIV and AIDS. It is an ethnographic case study in which participant observation and interviews were used. The data collected is organized in cultural domains which were: family living before and after the diagnosis; communicaton process of the pesons with HIV and AIDS and their families; expression of family support after developing aids; family coping with homossexuality. The central focus of the study enphazises feelings of solitude and isolation of these people, and the importance of the support in the adaptation in the new life style. This study demontrates the need of nursing intervention with other health professionals with the families and clients for them to find new ways of life and to make possible humanization of care.

KEY WORDS: Family; Nursing care; HIV.

\section{REFERÊNCIAS BIBLIOGRÁFICAS}

1. BUNTING, S.M. Persons with AIDS and their family caregivers: negotiating the journey. JFN, v.2, n.4, p.399-417, 1996.

2. BURY,M. Health and ilness in a changing society. London : Routledge, 1997.

3. FERRAZ, A.F. Refletindo sobre o ser portador do HIV ou doente com AIDS e o relacionamento interpessoal. IN: Silva, R.J.(Org.) Ação e vida: Belo Horizonte, Secretaria Municipal de Saúde, 1996.

4. GUALDA, D.M.R. Humanização no processo de cuidar. IN: CIANCIARULLO,T. et al. A hemodiálise em questão: opção pela qualidade assistencial. São Paulo : Ícone, 1998.

5. MENEGHIN, P. Entre o medo da contaminação pelo HIV e as representações simbólicas da AIDS: o espectro do despertar contemporâneo. Rev. Esc. Enf. USP, v.30, n.3. p.399-415. 1996.

6. LUDKE, M.M.; ANDRÉ, M.E.D. A pesquisa em educação: abordagens qualitativas. São Paulo : EPU, 1996.

7. LEININGER, M.M. Cultural care and universality: a theory of nursing. New York : National League for Nurses, 1991.

8. SPRADLEY, J. The ethnographic interview. New York, Hoet : Renehart and winston, 1979.

9. SILVA, R. J .O apoio psicológico aos portadores do HIV/AIDS. In: Ação e vida:respostas à epidemia de HIV/ AIDS em Belo Horizonte. Secretaria Municipal de Saúde, 1996. p.179-208.

10. STEFANELLI, M.C. Comunicação com o paciente: teoria e ensino. 2. ed. São Paulo : Robe,1993. 
